\title{
Contraceptive Use, Birth Spacing, and Autonomy: An Analysis of the Oportunidades Program in Rural Mexico
}

\author{
Becca S. Feldman, Alan M. Zaslavsky, Majid Ezzati, Karen E. Peterson, \\ and Marc Mitchell
}

\begin{abstract}
Oportunidades, a conditional cash-transfer program instituted in Mexico in 1997, provides cash incentives to mothers to invest in the health and education of family members. Drawing from data gathered by Mexico's National Institute of Public Health, this study assesses the effect of the program on contraceptive use and birth spacing among titulares (female household heads) living in rural areas during the experimental period, 1998-2000, and during 2000-03, after incorporation of the control group. In 2000, titulares were more likely to use modern contraceptives than were women in the control group, although by 2003 all beneficiaries had the same probability of use. Change in autonomy was not a mediator, although baseline autonomy modified the program's influence on contraceptive use. Cox proportional hazard models produced estimates that birth spacing was similar between the beneficiaries and controls. Inconsistent findings may be the result of the way contraceptive use was defined in this study. Findings from this study may be useful for helping program planners better understand the role of conditional cash transfers in modifying family planning and fertility among poor rural women in Latin America. (STUdies IN FAMILY PlanNing 2009; 40[1]: 51-62)
\end{abstract}

Increasing the use of family planning methods and decreasing fertility levels are important components of the development strategies of many poor countries. Throughout Latin America and the Caribbean, a number of countries have experienced marked changes in this sphere during the past three decades. The contraceptive

Becca S. Feldman is a postdoctoral fellow, Braun School of Public Health and Community Medicine, Hebrew University and Hadassah Medical Center, P.O. Box 12272, Jerusalem, 91120, Israel.E-mail: beccaf@ekmd.huji.ac.il. Alan M. Zaslavsky is Professor, Department of Health Care Policy, Harvard Medical School. Majid Ezzati is Associate Professor and Marc Mitchell is Lecturer on International Health, Department of Global Health and Population and Department of Environmental Health, Harvard School of Public Health. Karen E. Peterson is Professor, Department of Environmental Health Sciences, University of Michigan School of Public Health. prevalence rate in the region has risen from 38 percent to 73 percent (UN Population Division 2003), and total fertility rates have declined from 5.1 children per woman in the mid-1970s to 2.5 children in 2005 (PRB 2005). Mexico exemplifies these trends, primarily because of a focused, target-oriented population policy that emerged in the 1970s (Potter 1999). Among rural women, however, most of whom are poor, contraceptive prevalence remains low, and rates of reproduction and of accompanying maternal morbidity and mortality remain high (Gómez de León and Hernández 1998; WHO 2002). Mexico's 1995 National Family Planning Survey found that 46 percent of women living in rural areas used contraceptives, whereas 68 percent of urban women used them, and that poor rural women had a total fertility rate that was two times that of better-off urban women (Gómez de León and Hernández 1998). Much of this disparity is fueled by large inequalities between rural and urban residents in areas such as education, employment, and women's status (Flórez Nieto and Núñez 2001; UNFPA 2003). Programs that assist women to overcome these inequalities have become an important strategy for helping them gain 
control over their sexual and reproductive lives (Buvinic 1998; Gwatkin 2003).

Several Latin American governments have addressed rural poverty during the past decade by implementing large-scale conditional cash-transfer programs (CCTs). This new approach to poverty alleviation provides cash incentives to households to invest in the health and education of family members. Oportunidades (formerly PROGRESA) pioneered the CCT in 1997, and many countries in the region have followed suit, adopting similar program designs and evaluation strategies. Oportunidades is innovative in its provision of two types of transfers to the titulares (female household heads): one for household purchases, which is conditional upon family members' complying with health-promoting activities, and one for education, conditional upon children's school attendance. The objective of Oportunidades was not to introduce new facilities but rather to place emphasis on regular healthcare visits, to set up monitoring systems, and to provide extra training to personnel within the existing services and infrastructure (Skoufias 2005). The program was able to address these objectives because of the existence of community health clinics and hospitals that had been created in the 1970s by the Ministry of Health. Under Oportunidades, family planning programs were initiated and health-care providers were trained to provide information about and encourage the use of contraceptives. Consequently, although the primary objectives of Oportunidades were to improve household economics, children's schooling, and nutrition levels, it was implemented in a context where an emphasis on family planning already existed, providing the program with a chance to modify contraceptive use and fertility outcomes.

Previous evaluations of the impact of Oportunidades on contraceptive use among rural women in families enrolled in the program yielded inconsistent results. Two evaluations conducted in 2000 found increased use among women aged 20-49 who had given birth within three years following enrollment (Huerta and Hernández 2000) and among women aged 14-49 (Stecklov et al. 2006). Hernández Prado and his colleagues (2005) found no increase in contraceptive use, however, among women aged 15-49 in 2000 or in 2003, when comparing women enrolled in Oportunidades for four versus six years. Stecklov and his colleagues (2006) also found no evidence of a program effect on fertility levels among women aged 14-49. To date, no study has assessed the program's influence on the titulares' reproductive behaviors.

The subsample of titulares is of interest because the program, which transfers cash directly to the female heads of household and encourages their greater involve- ment in family welfare, may reduce gender inequality by improving women's autonomy and bargaining positions within their households (Gómez de Leon and Parker 1999; Adato et al. 2000). Autonomy has increased among the titulares, as demonstrated by both qualitative and quantitative evaluations. As a result of the program, titulares were found to have greater independence in spending money and purchasing goods for the household, to have greater opportunities to discuss issues of concern to them, and to receive greater recognition of the importance of their roles within the household (Adato et al. 2000; de la Brière and Quisumbing 2000). Other studies of autonomy and empowerment have found that such domains are associated with increased contraceptive use and lower fertility (Cleland and Wilson 1987; Mason 1986; Mason and Smith 2000). Malhotra and her colleagues (2002) reviewed nine studies assessing the association between various dimensions of autonomy and contraceptive use and found that women who were more involved in household decisionmaking were more likely to use a family planning method. Further studies conducted in Bangladesh, Egypt, and Nigeria also found that women's control of financial resources in the household was positively associated with the practice of contraception (Schuler and Hashemi 1994; Govindasamy and Malhotra 1996; Kritz et al. 2000).

In this study, we used the Oportunidades baseline and evaluation surveys to address the following questions: (1) Did Oportunidades increase contraceptive use among titulares during the two- and six-year evaluation period? (2) Did Oportunidades affect the timing of births among the titulares during the six-year evaluation period? (3) Was autonomy a mediator or modifier of the association between program participation (enrollment in Oportunidades) and contraceptive use?

\section{Methods}

\section{Eligibility for Program Participation}

Oportunidades provides cash transfers to designated female household heads, termed titulares, that are equal to approximately 20 percent of the families' preprogram monthly household expenditures (Skoufias et al. 1999). The transfers are conditioned on the following requirements: (1) children aged 8-18 are enrolled in school and maintain attendance rates greater than 85 percent; (2) all family members have access to a basic package of health services and obtain routine checkups at a health center included in the packages (health requirements vary by age group); (3) titulares attend public health talks that 
feature rotating topics, including adolescence and sexuality, family planning, HIV / AIDS, and sexually transmitted infections; and (4) pregnant women attend five antenatal visits, and both they and their children younger than two years of age take nutritional supplements. Two postpartum visits are also required, when mothers take their children for checkups at 7 and 28 days, which include family planning and maternal nutritional advice (Skoufias et al. 1999).

Eligibility for Oportunidades households was determined via a two-stage process. First, poor communities were identified from the 1995 national census based on an index of "marginality." Approximately 50,000 poor communities were identified in 31 states throughout Mexico. These included both rural and urban communities, although the initial beneficiaries lived in rural communities with fewer than 2,500 inhabitants; urban communities were incorporated in 2001. From these identified communities, low-income households in rural areas were selected through a proxy-means test based on characteristics collected via a census conducted in 1997. Approximately 78 percent of households in all of the communities were eligible for program benefits, and households were informed of their eligibility via door-to-door visits. Almost all (97 percent) of the eligible families enrolled (Skoufias et al. 1999).

Several mechanisms were put in place to minimize corruption on the program side and adherence on the participant side. First, Oportunidades established offices separate from existing government offices to manage the cash transfers. To improve local accountability, these offices published lists of the households that received the benefits (Gertler 2000). Second, in order for the titular to receive the cash transfer, medical providers had to certify that all family members had completed the required health-related activities. Approximately 1 percent of the households were denied the household cash transfers as a result of noncompliance (Skoufias 2005). Third, registration and attendance records were compiled at schools and presented to Oportunidades to determine whether enrolled children's attendance requirements had been met (Skoufias 2005).

\section{Experimental Design}

Evaluation of Oportunidades was part of the program's design and implementation. Because of financial constraints, not all of the communities across Mexico found to be eligible for the program were enrolled simultaneously. The government scheduled a group of communities to receive the benefits immediately and the rest to receive them at a later date. This enabled the program to select treatment and control groups randomly. About 10 percent (506) of the rural communities were selected across seven states; 320 were assigned to the treatment group and 186 to the control group. None of the communities assigned to the control group was told that it would be provided with benefits at a later date. All of the experimental communities-treatment and control groups-had the same level of poverty and similar characteristics (Behrman and Todd 1999).

\section{Data Collection}

Between 1997 and 2003, the National Institute of Public Health (INSP) in Mexico carried out large-scale evaluation surveys with all households in the 506 communities. Two baseline surveys were collected, the ENCASEH (Survey of Household Socioeconomic Characteristics) census in 1997 and the ENCEL (Evaluation Questionnaires) in 1998, which were followed by additional ENCEL and specialty modules throughout the evaluation period. Field-workers went house to house every six months to survey adults in both eligible and ineligible households in the experimental communities. Although only the eligible households in the beneficiary communities received Oportunidades benefits, ineligible households served an evaluation purpose as a future control group after the early control group was incorporated, and also allowed for the assessment of program spillover effects. The experimental period of the evaluation lasted two years (1998-2000): the early beneficiaries were offered Oportunidades benefits in early 1998, and the controls-the eligible households living in the control communities-began to receive them early in 2000.

\section{Data and Sample}

The data used in this study were drawn from the Oportunidades surveys conducted among eligible households selected in rural communities between 1997 and 2003 (see Figure 1). Data for the contraceptive-use analysis were obtained from four surveys: the 1997 baseline ENCASEH and the 1998 baseline ENCEL (both of which obtained information on demographics, socioeconomic status, family background, reproductive health and fertility, and health status and method-use characteristics of individuals and households), and the 2000 and 2003 ENCEL fertility modules. The 2003 fertility and reproductive health survey was administered only to a random sample of women of reproductive age (15-49 years) drawn from the larger 2003 ENCEL sample. Consequently, the merged sample 
Figure 1 Oportunidades survey timeline in rural areas, Mexico

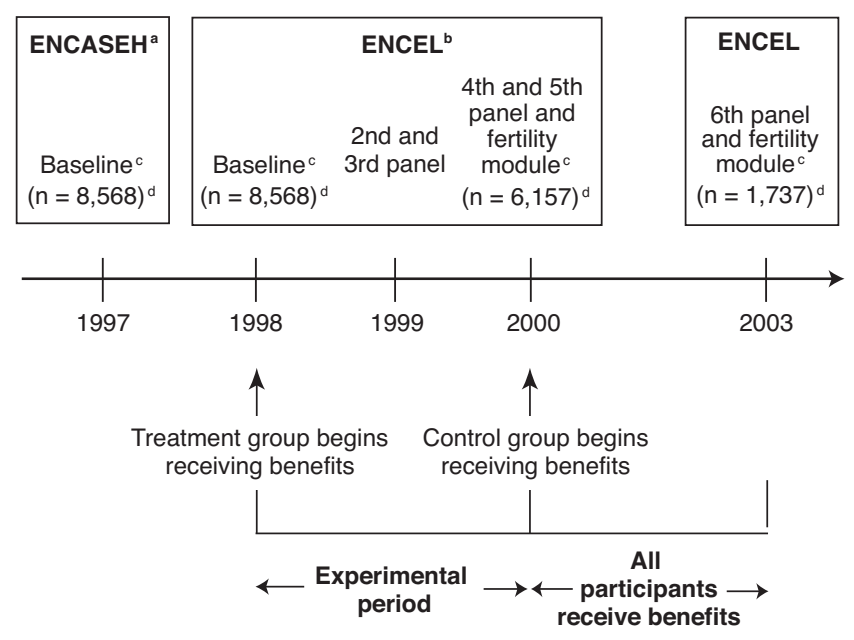

a Survey of Household Socioeconomic Characteristics. ${ }^{\mathrm{b}}$ Evaluation questionnaires. 'Surveys used in this study. $\quad{ }^{d} n=$ sample size used in this study. Note: Surveys were conducted by Mexico's National Institute of Public Health. Source: Hernández Prado et al. (2005).

used in the contraceptive-use analysis included 8,568 women at baseline, 6,157 of whom were interviewed in 2000 and 1,737 of whom were interviewed in 2003. We included both the 2000 and 2003 survey waves in the analysis because we were interested in assessing the impact of no program exposure versus exposure in 2000, and in assessing program participation for six years (from 1998 to 2003) versus participation for four years (from early 2000 to late 2003).

Birth-history data were drawn from the 2003 ENCEL survey, which collected information on all live births. The sample for the birth-spacing analysis was created by merging titulares and controls identified in the 2003 ENCEL sample with those already identified in the 1998 and 2000 samples to form a cohort of 5,001 women. Women who reported births less than nine months apart (that were not twins), those who reported births with incorrect chronology, and those who did not report the birth of a child during the evaluation period were excluded from the analysis.

The data used here were limited to all eligible women in the beneficiary and control communities who were identified as titulares (in the case of the beneficiaries), or who were married to or were the heads-of-household and became titulares two years later (in the case of the controls). For consistency, we call women "titulares" if they started to receive the cash transfer in 1998, and "controls" (the cross-over group) if they started to receive the cash transfer at the beginning of 2000. We use the term "program participation" to denote titular versus control status, and "stages of program participation" to indicate titular versus control status at each survey wave.

\section{Variables}

The survey source and method of coding for each of the dependent and independent variables examined in the study are presented in Appendix Table A1. The dependent variables were: current modern contraceptive use, current use of any contraceptive method, and birth spacing. Current modern contraceptive use was coded as 1 if the participant reported using any modern method of birth control, including condoms, oral contraceptives, intrauterine devices (IUDs), hormonal injectables, or female or male sterilization, and as 0 if she reported not currently using a method or if she had used a traditional method (periodic abstinence, withdrawal, or teas/herbs). Current contraceptive use of any method was coded as 1 if the participant reported using either a modern or traditional method or as 0 if she was not using any method. Birth spacing was assessed by estimating the occurrence and timing of each birth subsequent to a postbaseline index birth.

Baseline independent variables that have been found to influence both contraceptive use and timing of births were included in the models. These included age, educational level, literacy, employment status, autonomy level (defined below), indigenous household (when the titular reported speaking an indigenous language), monthly expenditures per capita (household expenditures for food and nonfood items), and number of live children. The birth-spacing model included parity of the index birth rather than number of children as a predictor in order to try to capture the number of children a woman reported having borne rather than the number of children currently in the family.

Questions regarding women's status in the household were asked in a similar format only in the 1998 and 1999 ENCEL surveys. Five overlapping questions about women's autonomy were identified and pertained to the domains of household and financial decisionmaking. The questions asked were about who makes decisions regarding children (attending school, going to the doctor, and purchasing clothes), spending money on household items, and spending when the titular has extra money. The answers were scored as follows: makes decision by herself (3 points), makes decisions jointly with her husband ( 2 points), and husband makes decisions (1 point), based on Gómez de León and Parker's (1999) analysis of empowerment among women in Oportunidades and on research conducted by Casique (2001) and Saleem and Bobak (2005). 
The five-item scores were summed, yielding an autonomy index ranging from 5 (husband makes all of the decisions) to 15 (woman makes all of the decisions independently). Cronbach's coefficient alpha, which assessed internal consistency of the scale, was 0.70 in 1998 and 0.78 in 1999.

\section{Statistical Analysis}

We began our analysis by merging the four survey waves and assessing for attrition among the titulares and controls in 2000 and 2003. Attrition rates in 2000 were high but similar for titulares (28 percent) and controls ( 29 percent). Attrition rates of individuals in other Oportunidades evaluation studies were found to be close to 22 percent of those originally interviewed in 1997 (Parker and Teruel 2005). The levels of attrition found in this study may be higher because the 2000 fertility survey interviewed all women of reproductive age in the household, regardless of whether the titular was present or not. Attrition in the 2003 fertility sample used here was less easily determined because of the sampling strategy. In 1998 and 2000, the probabilities of inclusion were 0.40 (controls) and 0.60 (titulares). The sampling frame for the fertility survey changed in 2003, and the titulares and controls had an equal probability of being included; thus, which women were not included in the sample because of the sampling frame and which had dropped out could not be determined. We also assessed nonrandom cohort attrition by comparing baseline characteristics of titulares and controls at each survey wave.

Second, we assessed the association between program status and modern contraceptive use and subsequently estimated a model with the outcome redefined to assess the effect of the program on use of any modern or traditional method of contraception. Logistic regression models were estimated combining all time points, employing generalized estimating equations (GEEs) and an exchangeable correlation option. GEEs enabled us to take into account clustering by community and serial correlation of longitudinal observations, and accounted for data missing completely at random so that we could exploit the larger data sets available for 1998 and 2000.

Third, the program's impact on birth spacing was assessed. Women giving birth at least once during the sixyear evaluation period made up the study cohort, and their first birth within the period was considered the index birth. We decided to define index births in this way in order to assess whether exposure to Oportunidades at the time of delivery affected the timing of a subsequent birth. We used a proportional-hazards survival model to assess the time-dependent hazard of a subsequent live birth dur- ing the evaluation period, using time in months. Followup for each woman ended at the second pregnancy or at the 2003 survey, and women with no subsequent birth within this period were treated as right-censored. The model included five program-year dummy variables and their interactions with the treatment group to contrast the hazards of subsequent births in the treatment and control groups at each of the six years of the evaluation period. This enabled us to distinguish the program impact during the experimental (1998-2000) and the second evaluation (2000-03) periods.

Last, our secondary analyses assessed the role of autonomy in the association between program participation and contraceptive use. We grouped the 1998 and 1999 autonomy indexes into four range categories because the indexes, which ranged from 5 to 15 , were distributed asymmetrically, with more women falling between 5 to 10 , and fewer above 10. In fact, the greatest proportion of women scored a 10 in 1998 (titulares: 52 percent; controls: 51 percent) and in 1999 (titulares: 47 percent; controls: 49 percent). The skewed form of the variable was not appropriate for inclusion in the GEE model, so we categorized the autonomy index to equalize numbers across groups. This classification yielded four autonomy groups: lowest (5-7), low (8-9), medium (10), and high (>10). We employed logistic regression models to estimate whether titulares experienced a differential increase in autonomy over the year compared with the controls. We added the 1998 and 1999 autonomy variables to the logistic regression model to assess whether the change in autonomy over the year mediated the association between contraceptive use in 2000 and program status. To do this, we assessed the change in the coefficient of program status when the autonomy variables were added to the model. We also assessed baseline autonomy (1998) as a modifier of the association between Oportunidades and contraceptive use by adding to the initial logistic model using GEEs a three-way interaction of 1998 autonomy, program participation, and time.

In all analyses, we adjusted standard errors for stratified sampling design and clustering of standard errors at the community level, which was the sampling unit. The analyses were conducted using SAS software, version 9.1.

\section{Results}

The titulares and controls had similar baseline characteristics, reflecting successful randomization (see Table 1). Frequencies and means of baseline variables were similar for titulares and controls in 1998, except that more 
Table 1 Percentage of Oportunidades titulares and controls, by baseline characteristics, according to survey wave, Mexico

\begin{tabular}{|c|c|c|c|c|c|c|}
\hline \multirow[b]{2}{*}{ Characteristic } & \multicolumn{2}{|c|}{1998} & \multicolumn{2}{|c|}{2000} & \multicolumn{2}{|c|}{2003} \\
\hline & $\begin{array}{l}\text { Titu- } \\
\text { lares }\end{array}$ & $\begin{array}{l}\text { Con- } \\
\text { trols }\end{array}$ & $\begin{array}{l}\text { Titu- } \\
\text { lares }\end{array}$ & $\begin{array}{l}\text { Con- } \\
\text { trols }\end{array}$ & $\begin{array}{l}\text { Titu- } \\
\text { lares }\end{array}$ & $\begin{array}{l}\text { Con- } \\
\text { trols }\end{array}$ \\
\hline (n) & $(5,362)$ & $(3,206)$ & $(3,904)$ & $(2,253)$ & $(973)$ & $(764)$ \\
\hline \multicolumn{7}{|l|}{ Maternal characteristic } \\
\hline \multicolumn{7}{|l|}{ Age } \\
\hline $15-24$ & 20 & 20 & 19 & 18 & 18 & 20 \\
\hline $24-29$ & 21 & 22 & 23 & 23 & 23 & 24 \\
\hline $30-39$ & 39 & 39 & 41 & 41 & 45 & 43 \\
\hline $40-49$ & 20 & 20 & 17 & 18 & 14 & 14 \\
\hline Ever attended school & 71 & 70 & 71 & 70 & 75 & 71 \\
\hline \multicolumn{7}{|l|}{ Educational level } \\
\hline None & 29 & 30 & 29 & 30 & 25 & 29 \\
\hline Primary incomplete & 44 & 43 & 45 & 43 & 47 & 42 \\
\hline Primary complete & 22 & 20 & 22 & 21 & 24 & 23 \\
\hline Secondary + & 5 & 6 & 5 & 6 & 4 & 6 \\
\hline Literate & 68 & 66 & 68 & 66 & 73 & 68 \\
\hline Worked in past week & $14^{* a}$ & $10^{\star a}$ & 12 & 9 & 10 & 9 \\
\hline Husband living in house & 99 & 99 & 99 & 99 & 99 & 99 \\
\hline \multicolumn{7}{|l|}{ Autonomy level } \\
\hline Lowest & 17 & 17 & 19 & 18 & 18 & 20 \\
\hline Low & 17 & 16 & 23 & 23 & 23 & 24 \\
\hline Medium & 50 & 52 & 42 & 41 & 45 & 43 \\
\hline High & 15 & 15 & 17 & 17 & 14 & 14 \\
\hline \multicolumn{7}{|l|}{$\begin{array}{l}\text { Household socioeconomic } \\
\text { characteristic }\end{array}$} \\
\hline Indigenous household & 40 & 40 & $45^{\star b}$ & 45 & $34^{* b}$ & 35 \\
\hline Dirt floors in house & 71 & 74 & 72 & 75 & 64 & 67 \\
\hline Bathroom in house & 52 & 51 & 55 & 53 & 55 & 46 \\
\hline Electricity in house & 60 & 63 & 59 & 61 & 60 & 68 \\
\hline $\begin{array}{l}\text { Monthly expenditure } \\
\text { (pesos) }\end{array}$ & 144.3 & 147.1 & 141.0 & 143.4 & 144.9 & 150.1 \\
\hline \multicolumn{7}{|l|}{$\begin{array}{l}\text { Characteristic related to } \\
\text { family planning }\end{array}$} \\
\hline Wants another child & 33 & 32 & 33 & 33 & 35 & 36 \\
\hline Number of children $(\geq 5)$ & 28 & 27 & 28 & 27 & 29 & 27 \\
\hline
\end{tabular}

*Significant at $\mathrm{p} \leq 0.05$.

a Significance reflects difference between titulares and controls in 1998. ' nificance reflects difference between titulares in 2000 versus 2003 .

Note: For all variables, chi-square tests were conducted to assess the significance of differences between (a) titulares and controls at each of the three time periods, (b) titulares in 1998 versus 2000 and in 2000 versus 2003, and (c) controls in 1998 versus 2000 and in 2000 versus 2003.

titulares than controls were working in the past week $(\mathrm{p}=0.04)$. Titulares and controls who participated in all three waves were similar to each other, except that there were more indigenous women in the treatment group in 2000 compared with 2003 ( $\mathrm{p}=0.05)$. This finding suggests that the study succeeded in attaining and maintaining balance between the groups.

Titulares and controls in the cohort were aged 15-49 at baseline, and the largest group (roughly 44 percent) had started but not completed elementary school. About two-thirds of the women were literate. Ninety-nine percent of the women lived with their husbands, and roughly half of the women reported a medium level of autonomy.
Forty percent lived in an indigenous household, about 72 percent lived in a house with dirt floors, and about half lived in a house with a bathroom. About a third of the women reported wanting to have another child, and 28 percent had five or more children.

\section{Contraceptive Use}

Among titulares and controls who reported using contraceptives at baseline, the majority used modern methods; on average, only 10 percent of users reported that they use traditional methods (not shown). At baseline, the titulares and controls reported comparable levels of modern contraceptive use (37 percent and 39 percent, respectively). An increasing proportion of women became modern contraceptive users with each subsequent survey wave. In 2000, 41 percent of the titulares and 39 percent of the controls were using a modern contraceptive method, and by 2003, 55 percent and 49 percent of the titulares and controls, respectively, were using modern contraceptives. Throughout the study period, among both titulares and controls, the most commonly used methods (independent of women's age or educational level) were the IUD and sterilization; a small proportion of women used hormonal injections, and a few reported using condoms with their partner ( $<5$ percent) (not shown).

In the adjusted model shown in Table 2, the titulares increased their modern contraceptive use between 1998 and 2000 significantly more than did the controls. In 2000, the titulares had a 0.23 increase in the log odds from baseline, whereas the controls had a 0.07 increase in the log odds, a difference in log odds of 0.16 , which is statistically significant at $p=0.02$. No differential increase was found in modern contraceptive use between baseline and 2003, when the controls had been enrolled in the program for four years and the titulares for six years, or between 2000 and 2003.

Modern contraceptive use was lower among 15-24year-old women than in the 25-29 and 30-39 age groups, but higher than in the 40-49 age group. Having attained a higher educational level, not working in the past week, and living in a nonindigenous household were positively associated with modern contraceptive use. The baseline levels of none of the variables modified or confounded the association between stage of program participation and modern contraceptive use.

The program effect diminished when the contraceptive-use outcome was redefined to include any type of contraceptive. At baseline, the titulares and controls were equally likely to use any type of method (42 percent and 43 percent; see Table 1), with statistically indistinguish- 
Table 2 Logistic regression analysis showing the difference in log odds between Oportunidades titulares and controls in modern contraceptive use over time, by stage of participation and other characteristics, Mexico, 1998-2003

\begin{tabular}{|c|c|}
\hline Characteristic & Log odds \\
\hline \multicolumn{2}{|c|}{ Stage of program participation a } \\
\hline At 1998 baseline & -0.06 \\
\hline From baseline to 2000 & $0.16^{\star}$ \\
\hline From baseline to 2003 & 0.16 \\
\hline \multicolumn{2}{|l|}{ Age } \\
\hline $15-24(r)$ & 0.00 \\
\hline $25-29$ & $0.12^{*}$ \\
\hline $30-39$ & $0.23^{* *}$ \\
\hline $40-49$ & $-0.28^{* *}$ \\
\hline \multicolumn{2}{|l|}{ Educational level } \\
\hline None & $-0.45^{\star *}$ \\
\hline Primary incomplete & $-0.24^{*}$ \\
\hline Primary complete & -0.09 \\
\hline Secondary+ $(r)$ & 0.00 \\
\hline Did not work in past week & $0.33^{\star *}$ \\
\hline \multicolumn{2}{|l|}{ Autonomy } \\
\hline Lowest & 0.06 \\
\hline Low & 0.03 \\
\hline Medium & -0.01 \\
\hline High (r) & 0.00 \\
\hline Indigenous household & $-0.38^{* *}$ \\
\hline Expenditure per capita & -0.01 \\
\hline$<5$ children & -0.08 \\
\hline
\end{tabular}

able probabilities in 2000 (44 percent and 42 percent) and in 2003 (61 percent and 55 percent). The adjusted model shows that during the first two years, the titulares increased their log odds of contraceptive use by 0.18 , whereas the controls had a 0.08 increase in log odds of use, which was a marginally statistically significant difference ( $p=0.055)$ (not shown). In 2003, the two groups had similar increases in the probability of contraceptive use over time from baseline (not shown).

\section{Birth Spacing}

Of the 5,001 women in the 2003 cohort, 2,377 (48 percent) had an index birth during the evaluation period, and of these women, 967 (41 percent) had at least one subsequent birth. The average birth interval (excluding censored cases) was similar for titulares (28.9 months) and controls (28.3 months).

In the proportional hazards models shown in Table 3 , titulares and controls had a similar likelihood of experiencing subsequent childbirths during the evaluation period (hazard ratio $=1.04 ; \mathrm{p}=0.41$ ). Interactions of pro-
Table 3 Respondents' hazard of giving birth subsequent to the index birth during each of the six years of the Oportunidades program-evaluation period (1998-2003), Mexico

\begin{tabular}{|c|c|c|c|}
\hline Characteristic & $\begin{array}{c}\text { Coefficient } \\
\text { estimate }\end{array}$ & $\begin{array}{r}\text { Standard } \\
\text { error }\end{array}$ & $\begin{array}{r}\text { Hazard } \\
\text { ratio }\end{array}$ \\
\hline Program participation ${ }^{a}$ & 0.04 & 0.05 & 1.04 \\
\hline \multicolumn{4}{|l|}{ Age } \\
\hline $15-24(r)$ & 0.00 & - & 0.00 \\
\hline $25-29$ & -0.41 & 0.06 & $0.67^{\star \star}$ \\
\hline 30-39 & -1.01 & 0.07 & $0.37^{\star *}$ \\
\hline $40-49$ & -2.62 & 0.17 & $0.07^{\star \star}$ \\
\hline High educational level ${ }^{\mathrm{b}}$ & -0.1 & 0.05 & $0.9^{\star}$ \\
\hline Did not work in past week & 0.13 & 0.09 & 1.14 \\
\hline \multicolumn{4}{|l|}{ Autonomy } \\
\hline Lowest & -0.03 & 0.09 & 0.97 \\
\hline Low & 0.04 & 0.09 & 1.05 \\
\hline Medium & -0.06 & 0.07 & 0.94 \\
\hline High (r) & 0.00 & - & 0.00 \\
\hline Nonindigenous household & -0.28 & 0.05 & $0.76^{* *}$ \\
\hline Expenditure per capita & 0.00 & 0.00 & 1.00 \\
\hline High parity ( $\geq 5$ ) & -0.05 & 0.07 & 0.95 \\
\hline
\end{tabular}

${ }^{*}$ Significant at $p \leq 0.05 ;{ }^{* *} p \leq 0.01 . \quad(r)=$ Reference group. $\quad-=$ Not applicable. ${ }^{a}$ Controls are reference group. ${ }^{\mathrm{b}}$ Education is coded as high (primary complete and higher) and low (primary incomplete and none).

gram year by program participation were not significant, indicating that titulares and controls had a similar likelihood of giving birth each year throughout the evaluation period. Older age, higher educational level, living in a nonindigenous household, and higher parity were associated with a lower hazard of experiencing a subsequent birth.

\section{Autonomy, Oportunidades, and Contraceptive Use}

Bivariate tabulations (not shown) comparing women of high autonomy with those having medium, low, and lowest autonomy found that autonomy at the baseline level was positively and significantly associated with several characteristics, including older age, higher educational level, and having worked in the past week. These associations were also found with the autonomy variable in 1999. Because similar questions about autonomy were asked only in the 1998 and 1999 surveys, the analysis of changes in autonomy was restricted to a comparison of data from these two years.

Overall, autonomy increased among all women between 1998 and 1999 ( $\mathrm{p}$ < 0.01) (not shown). In 1998, 15 percent of the titulares and controls fell into the high autonomy category, and a year later 27 percent were in that category. Approximately half of the women were in the medium autonomy category in 1998 (titulares: 50 percent; 
Table 4 Log odds of difference in rate of modern contraceptive use among titulares compared with controls, by stage of participation in Oportunidades, according to levels of autonomy, Mexico, 1998-2003

\begin{tabular}{lcr} 
Stage of program participation $^{\text {a }}$ & $\begin{array}{r}\text { Lowest autonomy } \\
\text { Log odds }\end{array}$ & $\begin{array}{r}\text { Higher autonomy } \\
\text { Log odds }\end{array}$ \\
\hline At 1998 baseline & -0.03 & -0.07 \\
From baseline to 2000 & $0.32^{* *}$ & 0.11 \\
From baseline to 2003 & 0.12 & 0.16
\end{tabular}

${ }^{* *}$ Significant at $p \leq 0.01$. $\quad$ a The reference group is the control group at all time points. ${ }^{b}$ Higher autonomy encompasses the three highest autonomy categories (low, medium, high).

Note: Values represent calculated parameter estimates after controlling for age, educational level, having worked during the past week, living in an indigenous household, expenditure per capita, and parity.

controls: 52 percent) and in 1999 (titulares: 47 percent; controls: 49 percent).

A longitudinal analysis showed that titulares' autonomy increased more than that of the controls from baseline between 1998 and 1999 (log odds: 0.11; $\mathrm{p}=0.05$ ) (not shown). This increase did not mediate the association between program status and contraceptive use in 2000, however. Including the 1998 and 1999 autonomy variables in the adjusted contraceptive-use model changed the coefficient of the program-status variable by less than 10 percent. The autonomy index was disaggregated, and separate models were assessed for whether the individual autonomy items played a mediating role. None were found to be mediators in these analyses.

Baseline autonomy modified the association between program status and contraceptive use over time (see Table 4). In 2000, the titulares with the lowest autonomy increased contraceptive use from baseline more than did the controls $(p=0.01)$, whereas among those with higher autonomy (the low, medium, and high categories), the titulares and controls increased contraceptive use by the same amount $(\mathrm{p}=0.12)$. By 2003 , both the titulares and controls at all levels of autonomy had similar probabilities of contraceptive use. Interactions between stage of program participation and age, educational level, socioeconomic status, and parity at baseline were not significant (not shown), indicating a lack of evidence for modification of program effect by any of these characteristics.

\section{Discussion}

This study is the first to evaluate reproductive behavior among female cash recipients participating in the Oportunidades program. Oportunidades influenced contraceptive use among the titulares during the experimental pe- riod (1998 to 2000), but did not influence the subsequent birth spacing of women who gave birth during this period. Although changes in respondents' autonomy (as defined in this study) over the first year of enrollment did not mediate the program effect, evidence demonstrated that the titulares' baseline autonomy modified the effect on contraceptive use.

These findings confirmed those of other Oportunidades evaluations regarding the contraceptive behavior and fertility of female beneficiaries aged 14-49 and women aged 20-49 who gave birth within three years of baseline (Huerta and Hernández 2000; Stecklov et al. 2005) and contrasted with what others found among women aged 15-49 (Hernández Prado et al. 2005) after two years of program exposure. The current study found a small yet significant effect of the program on contraceptive use among titulares in 2000, in accordance with the small increase ( 2 percent; $\mathrm{p}=0.01$ ) that Stecklov and his colleagues (2006) found. A differential increase also was observed in contraceptive use between baseline and 2003 between the controls and titulares. Although this difference was not found to be statistically significant in the adjusted regression, the numbers suggest that the titulares who had been enrolled for six years were more likely to practice contraception than were those enrolled for four years. Hernández Prado and his colleagues (2005) also found that in 2003 a greater proportion of 1998 program beneficiaries used contraceptives during last sex, compared with the 2000 beneficiaries, although the difference was not significant.

We hypothesized that more time enrolled in the Oportunidades program would be associated with increased contraceptive use as a result of greater program involvement-for example, participation in health talks and contact with health-care providers. The absence of a differential program effect in 2003 could mean that Oportunidades successfully reached a segment of the titulares but that its program components were not relevant or appropriate for other cash recipients. Social and cultural factors such as religious beliefs or the influence of mothers-in-law may be barriers that prevent the program from reaching many of the beneficiaries. Follow-up studies of program effects for a more extended period are needed to assess whether this flattening trend continues and, if so, why. A continued plateau in the program after three years would be of concern, particularly because the titulares in 2003 still did not reach the countrywide contraceptive prevalence of 70 percent (UNDP 2003).

Despite a small increase in the use of family planning methods in 2000, Oportunidades did not affect birth spacing among the titulares over the six-year evaluation pe- 
riod. Stecklov and his colleagues (2006) similarly found that among female Oportunidades beneficiaries aged 1549 , contraceptive use increased by 2 percentage points but age-specific fertility rates remained stable. We offer two possible explanations for the program's surprising lack of effect on birth spacing, given that contraceptive use-one of the primary proximate determinants of fertility (Bongaarts and Potter 1983)—increased. First, male migration to the United States appears to have decreased as a result of the Oportunidades program (Stecklov et al. 2005), and with more men at home, suggest Stecklov and his colleagues (2006), there may be a greater frequency of intercourse and, consequently, an increased demand for contraception without a corresponding decline in fertility. Second, the lack of correspondence between contraceptive use and birth spacing might have been a consequence of our narrow definition of contraceptive use-namely, use of modern methods. When the contraceptive-use outcome was subsequently redefined to include both modern and traditional methods, only a borderline statistical difference in use was found between titulares and controls in 2000. Studies in both developed and developing countries have found that traditional methods-such as periodic abstinence, withdrawal, the Billings ovulation method, and lactational amenorrhea-can be used effectively to limit failure rates to as low as 2 percent to 9 percent in the first year (Ryder and Campbell 1995; Sinai et al. 1999). Therefore, if the program's effect has been to enable women to switch from traditional to modern contraceptive methods, Oportunidades would have no impact on birth spacing.

Autonomy did not emerge as a mediator of the effect of Oportunidades on contraceptive use. This finding may be the result of the limited domains of autonomy measured for the study. Autonomy is a multidimensional concept, and measures of any single domain, such as household decisionmaking, define the concept too narrowly (Balk 1994). In rural Mexico, greater participation in household decisionmaking might not translate into more contraceptive use, particularly among young, newly married women, who may still face barriers to controlling their fertility such as cultural stigma and the expectations of family members, particularly mothers-in-law. Other domains of autonomy, such as the connection to social networks, freedom from threat, or the ability to initiate activities and carry them out, may be more closely associated with overcoming societal barriers to contraceptive use in this context (Kritz et al. 2000; Mason and Smith 2000; Malhotra et al. 2002).

Baseline autonomy was found to modify the relationship between Oportunidades and contraceptive use between 1998 and 2000, although this effect was limited to the least autonomous titulares. The more autonomous women were more likely to have had greater knowledge of and access to contraception than others before enrollment, possibly as a result of their greater exposure to the media, greater mobility, and more frequent contact with health-care services and promoters. Conversely, the least autonomous women-who were more likely to be poor, to be indigenous, and to have low levels of literacy and educational attainment-were introduced to resources and services that previously had not been available to them. Consequently, they may have been more likely to adopt and benefit from the tools and knowledge provided by the program. Oportunidades aims to improve outcomes among all women, however. Inclusion in future evaluation surveys of the autonomy questions from the other suggested domains is necessary for determining whether and how all titulares' autonomy continues to change over the long term.

\section{Strengths and Limitations of the Analysis}

The analysis is limited by the experimental design, which restricted treatment/control comparisons to a two-year period. Although this period is appropriate for assessing short-term effects, estimating medium-term effects such as timing of births is difficult; we could make comparisons based only on differential exposure to the program's benefits (six versus four years). Although other evaluators (Behrman et al. 2004; Gertler and Fernald 2004; Hernández Prado et al. 2005) have employed nonexperimental designs such as matching to a new comparison group in 2003, for this study we chose to rely solely on the randomized design.

We noted above the narrowness of the domains of autonomy, but perhaps a greater limitation was the measurement error in the autonomy variable, which might have attenuated the observed relationships between enrollment in Oportunidades and contraceptive use. The correlation between autonomy in 1998 and in 1999 was only 0.17 , which suggests low reliability for measures collected only a year apart. The household surveys used might not have been sensitive measures of family dynamics if the complexities of the spousal negotiation process were difficult to describe with multiple-choice questions (Adato et al. 2000).

The birth-spacing analysis was limited by the restriction of the cohort to respondents with an index birth during the evaluation period. If the effect of the program was to cause the titulares to delay their pregnancies, our analysis cohort might overrepresent women who were 
less responsive to the program and thus more likely to give birth subsequently, thus attenuating the program estimates. Furthermore, the analysis does not take into account women who did not give birth during the evaluation period. If a segment of the cohort responded to Oportunidades by having no more children, our analysis would not capture this program effect. Lastly, because of data limitations, we analyzed time to subsequent live birth in this study rather than time to conception. In a subsample of women who completed the 2003 fertility module, frequencies of stillbirths were similar in the two groups (8 percent), but abortions / miscarriages were more frequent among the titulares than among the controls (19 percent versus 14 percent; $\mathrm{p}=0.03$ ) (not shown). If similar differences exist for the full cohort used in this study, the birthspacing estimates for the titulares might be upwardly biased relative to spacing between conceptions.

The study also has several strengths. This is the first analysis of Oportunidades to assess whether the autonomy of the titulares plays a role in the association between contraceptive use and program status. Although we did not find that change in autonomy over a one-year period mediates the association, we provided initial findings and proposed future questions for advancing the understanding of the causal mechanisms through which Oportunidades might influence titulares' contraceptive behaviors.

Studies of program effects on women's autonomy often confront the problem that women with certain char- acteristics, such as higher education and better health, are more likely to enroll in health-related programs. In the absence of adequate controls, such confounding characteristics may bias the estimates of the programs' effects. The randomized design of the Oportunidades evaluation controls for such confounding. Furthermore, both experimental groups have equal access to health-care centers, because the presence of such a center in the community or near all households in the community was a criterion for eligibility.

Our findings suggest that conditional cash transfers to women have a role in increasing their contraceptive use, especially among women who enter the program with low levels of autonomy. The program's lesser effects on women with higher levels of autonomy are also important, however, because their baseline contraceptive use is still much lower than the countrywide average.

Future research should employ nonexperimental methods as well as ethnographic approaches to assess how conditional cash transfers affect beneficiaries' reproductive behaviors over a longer period of time. Program boosters, which introduce modifications and innovations to the program, such as introducing new tools to convey information in the family planning talks or providing employment workshops for the titulares to increase morale and promote financial opportunities, may be necessary to maintain and increase program affiliation that eventually leads to changes in fertility in this population.

\section{Appendix}

Table A1 Model covariates, descriptions, and data sources, analysis of Oportunidades Program, Mexico, 1997-2003

\begin{tabular}{|c|c|c|}
\hline Variable & Coding value & Source \\
\hline \multicolumn{3}{|l|}{ Dependent variable } \\
\hline Current modern contraceptive use & 1 (modern methods); 0 (not using or using traditional methods) & 1998 ENCEL; 2000 and 2003 fertility surveys \\
\hline Current use of any contraceptive method & 1 (modern or traditional); 0 (not using any method) & 1998 ENCEL; 2000 and 2003 fertility surveys \\
\hline Birth spacing & $\begin{array}{l}\text { Occurrence and timing of each birth subsequent to a } \\
\text { postbaseline index birth }\end{array}$ & 2003 ENCEL \\
\hline \multicolumn{3}{|l|}{ Independent variable } \\
\hline Age & $15-24,25-29,30-39,40-49$ & 1997 ENCASEH $^{d}$ \\
\hline Educational level & None, primary incomplete, primary complete, and secondary+ & 1997 ENCASEH \\
\hline Literacy & Yes/no & 1997 ENCASEH \\
\hline Worked in the past week & Yes / no & 1998 ENCEL \\
\hline Autonomy & Lowest, low, medium, high & 1998 ENCEL \\
\hline Indigenous household & Yes / no & 1997 ENCASEH \\
\hline Monthly expenditure per capita & Continuous & 1998 ENCEL \\
\hline Number of children ${ }^{a}$ & $<5 / \geq 5$ & 1997 ENCEL \\
\hline Parity ${ }^{\mathrm{b}}$ & High $(\geq 5) ;$ low $(<5)$ & 1997 ENCASEH \\
\hline
\end{tabular}




\section{References}

Adato, Michelle, Bénédicte de la Brière, Dubravka Mindek, and Agnes Quisumbing. 2000. The Impact of PROGRESA on Women's Status and Intrahousehold Relations. Final Report. Washington, DC: International Food Policy Research Institute.

Balk, Deborah. 1994. "Individual and community aspects of women's status and fertility in rural Bangladesh." Population Studies 48(1): $21-45$.

Behrman, Jere R., Susan W. Parker, and Petra E. Todd. 2004. “MediumTerm Effects of the Oportunidades Program Package, including Nutrition, on Education of Rural Children Age 0-8 in 1997." Technical Document No. 9 on the Evaluation of Oportunidades 2004. <http: / / www.sarpn.org.za/documents / d0001264/P1499-9_Behrman_ed_ rural_23nov04.pdf >. Accessed July 2006.

Behrman, Jere and Petra Todd. 1999. A Report on the Sample Sizes Used for the Evaluation of the Education, Health, and Nutrition Program (PROGRESA) of Mexico. Methodology Report. Washington, DC: International Food Policy Research Institute.

Bongaarts, John and Robert G. Potter. 1983. Fertility, Biology, and Behavior: An Analysis of the Proximate Determinants. New York: Academic Press.

Buvinic, Mayra. 1998. "The costs of adolescent childbearing: Evidence from Chile, Barbados, Guatemala, and Mexico." Studies in Family Planning 29(2): 201-209.

Casique, Irène. 2001. "What difference does it make? Women's autonomy and power and use of contraception in Mexico." Paper presented at the XXIV IUSSP General Population Conference, Salvador, Bahia, August.

Cleland, John and Christopher Wilson. 1987. "Demand theories of the fertility transition: An iconoclastic view." Population Studies 41(1): 5-30.

de la Brière, Bénédicte and Agnes Quisumbing. 2000. The Impact of PROGRESA on Intrahousehold Decision Making and Relative Schooling Achievements of Boys and Girls. Report. Washington, DC: International Food Policy Research Institute.

Flórez Nieto, Carmen Elisa and Jairo Núñez. 2001. "Teenage childbearing in Latin American countries." Universidad de Los Andes: Centro de Estudios sobre Desarrollo Económico (CEDE). <http: / / www.iadb.org/res/publications/pubfiles/pubR-434.pdf $>$. Accessed March 2006

Gertler, Paul. 2000. The Impact of PROGRESA on Health. Final Report. Washington, DC: International Food Policy Research Institute.

Gertler, Paul J. and Lia C. Fernald. 2004. The Medium Term Impact of Oportunidades on Child Development in Rural Areas. Final Report. Berkeley, CA: University of California-Berkeley and Instituto Nacional de Salud Pública, Mexico.

Gómez de León, José and Daniel Hernández. 1998. "Poverty and contraceptive use in rural Mexico." Paper presented at the Poverty, Fertility, and Family Planning seminar, Mexico City, 2-4 June.

Gómez de Leon, José and Susan Parker. 1999. The Impact of Anti-Poverty Programs on Labor Force Participation. PROGRESA. Unpublished.

Govindasamy, Pavalavalli and Anju Malhotra. 1996. "Women's position and family planning in Egypt." Studies in Family Planning 27(6): 328-340.
Gwatkin, Davidson R. 2003. "How well do health programmes reach the poor?" Lancet 361(9,357): 540-541.

Hernández Prado, Bernardo, José Edmundo Urquieta Salomón, María Dolores Ramírez Villalobos, and José Luis Figueroa. 2005. “Impacto de Oportunidades en la salud reproductiva de la población beneficiaria." In Evaluación Externa de Impacto de Programa Oportunidades 2004. Eds. Bernardo Hernández Prado and Mauricio Hernández Ávila. Mexico, D.F.: Instituto Nacional de Salud Pública, Mexico. Pp. 121-174.

Huerta, Ma. del Carmen and Daniel Hernández. 2000. "Algunos aspectos de salud reproductiva de la población beneficiaria de Progresa." In Progresa. Más Oportunidades para las Familias Pobres. Mexico City: SEDESOL (Secretaría de Desarrollo Social).

Kritz, Mary, Paulina Makinwa-Abebusoye, and Douglas Gurak. 2000. "The role of gender context in shaping reproductive behaviour in Nigeria." In Women's Empowerment and Demographic Processes: Moving Beyond Cairo. Eds. Harriet B. Presser and Gita Sen. New York: Oxford University Press. Pp. 239-260.

Malhotra, Anju, Sidney Ruth Schuler, and Carol Boender. 2002. "Measuring Women's Empowerment as a Variable in International Development." Paper commissioned by the Gender and Development Group of the World Bank. Unpublished.

Mason, Karen Oppenheim. 1986. "The status of women: Conceptual and methodological issues in demographic studies." Sociological Forum 1(2): 284-300

Mason, Karen O. and Herbert L. Smith. 2000. “Husbands' versus wives' fertility goals and use of contraception: The influence of gender context in five Asian countries." Demography 37(3): 299-311.

Parker, Susan W. and Graciela M. Teruel. 2005. "Randomization and social program evaluation: The case of Progresa." The Annals of the American Academy of Political and Social Science 599(1): 199-219.

Population Reference Bureau (PRB). 2005. Women of Our World. Washington, DC: PRB.

Potter, Joseph E. 1999. "The persistence of outmoded contraceptive regimes: The cases of Mexico and Brazil." Population and Development Review 25(4): 703-739.

Ryder, Bob and Hubert Campbell. 1995. "Natural family planning in the 1990s." Lancet 346(8,969): 233-234.

Saleem, Shababa and Martin Bobak. 2005. "Women's autonomy, education and contraception use in Pakistan: A national study." Reproductive Health 2:8. <http:/ / www.reproductive-health-journal. com $/$ content $/ 2 / 1 / 8>$. Accessed February 2009.

Schuler, Sidney Ruth and Syed M. Hashemi. 1994. "Credit programs, women's empowerment, and contraceptive use in rural Bangladesh." Studies in Family Planning 25(2): 65-76.

Sinai, Irit, Victoria Jennings, and Marcos Arévalo. 1999. “The two-day algorithm: A new algorithm to identify the fertile time of the menstrual cycle." Contraception 60(2): 65-70.

Skoufias, Emmanuel. 2005. "PROGRESA and its Impacts on the Welfare of Rural Households in Mexico." Research Report No. 139. Washington, DC: International Food Policy Research Institute.

Skoufias, Emmanuel, Benjamin Davis, and Jere Behrman. 1999. An Evaluation of the Selection of Beneficiary Households in the Education, Health, and Nutrition Program (PROGRESA) of Mexico. Washington, DC: International Food Policy Research Institute. 
Stecklov, Guy, Paul Winters, Marco Stampini, and Benjamin Davis. 2005. "Do conditional cash transfers influence migration? A study using experimental data from the Mexican PROGRESA program." Demography 42(4): 769-790.

Stecklov, Guy, Paul Winters, Jessica Todd, and Ferdinando Regalia. 2006. "Demographic Externalities from Poverty Programs in Developing Countries: Experimental Evidence from Latin America." American University Department of Economics Working Paper No. 2006-1. Washington, DC: American University.

United Nations Development Programme (UNDP). 2003. Human Development Report. New York: UNDP.

United Nations (UN) Population Division. 2003. “World Contraceptive Use." <http:/ / www.un.org/esa/population/publications / contraceptive2007/ contraceptive_2007_table.pdf >. Accessed July 2006.

United Nations Population Fund (UNFPA). 2003. The State of World Population. Giving Priority to Adolescents. New York: UNFPA.
World Health Organization (WHO). 2002. The World Health Report 2002: Reducing Risks, Promoting Healthy Life. Geneva: WHO.

\section{Acknowledgments}

The authors acknowledge the contribution of Sydney Atwood to the analysis of the data used in this study. Becca Feldman was a doctoral student at the Harvard School of Public Health while conducting the research and received funding from Harvard's Committee on General Scholarships. The data were collected by the National Institute of Public Health with funding from the Oportunidades program of the Mexican Ministry of Social Development and the Inter-American Development Bank. 